\title{
Collaborative Distance: Multi-level Analysis Framework for Recommending Collaboration Structure and Safeguards
}

\author{
Douglas C. Derrick \\ University of Nebraska Omaha \\ dcderrick@unomaha.edu
}

\author{
Gina S. Ligon \\ University of Nebraska Omaha \\ gligon@unomaha.edu
}

\author{
Erin P. Miles \\ University of Nebraska Omaha \\ erinpmiles@unomaha.edu
}

Leif W. Lundmark

University of Nebraska Omaha

llundmark@unomaha.edu
J. S. Elson

University of Nebraska Omaha

jelson@unomaha.edu

\begin{abstract}
We developed a framework that assists in capturing the differences between two organizations. Collaborative distance captures the degree of similarity between the cooperating organizations across four separate levels of analysis: sector, organization, functional, and individual. Organizations that are very similar to each other are said to have "low collaborative distance" and organizations that differ on important characteristics are said to have "high collaborative distance". We propose that this measure coupled with problem complexity ought to dictate the structure and safeguards for inter-organizational collaboration. We show a sample calculation of this measure.
\end{abstract}

\section{Introduction}

Today, partnership plays a key role for all types and forms of organizations, yet collaboration is notoriously difficult, fraught with loss of control, multiple and sometimes conflicting goals, and tension between accountability and autonomy [15]. Given that collaboration is no longer a choice but rather a necessity, this paper develops an innovative and integrative collaboration framework for analyzing collaborations and recommending structures and safeguards.

We took a multi-pronged approach to develop a model for collaboration and a framework for analyzing collaborative partners. The approach consisted of an academic literature review of scholarly articles about inter-organizational collaboration, conducting field interviews with collaborators in management positions across disparate fields, interviewing Subject-Matter Experts, and holding a focus group of government personnel, we devised a collaboration model and tools to help assess collaboration. The model outlines a three-stage process of inter-organizational collaboration and is outlined in Figure 1. The model can be used at the individual level and extrapolated to larger organizations and multi-team systems. The three stages consist of (1) Formulation, (2) Implementation, and (3) Outcomes and Evaluation. Each stage is discussed in detail below.

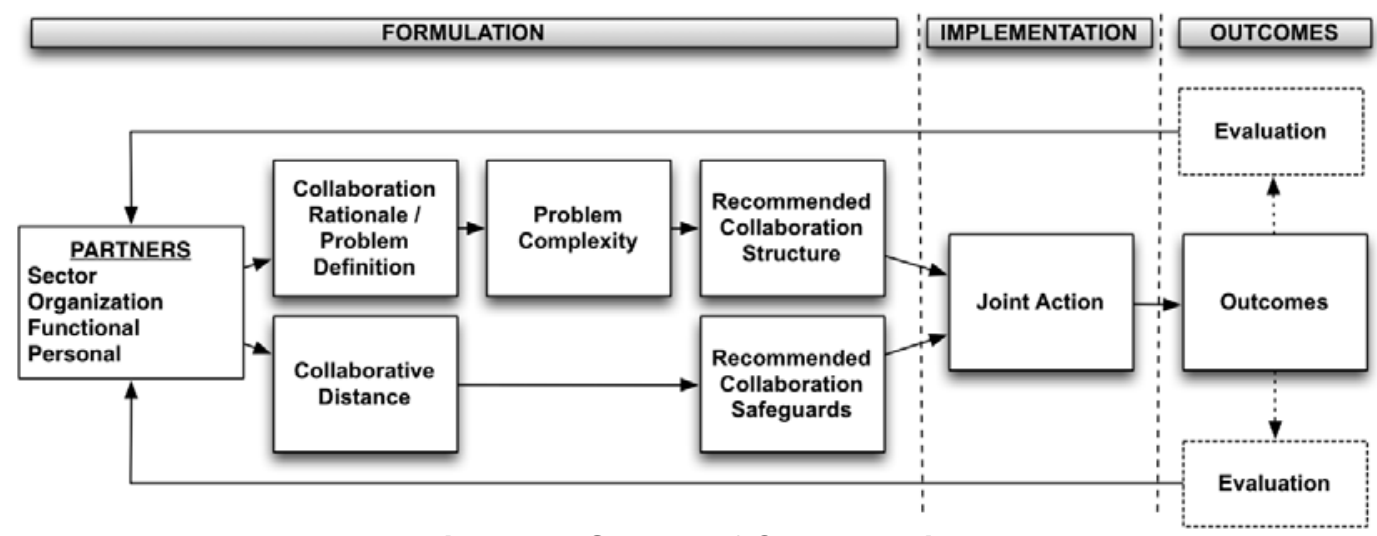

Figure 1. Stages of Collaboration 
However, our efforts have focused on providing an actionable Concept of Operations based on the formulation stage of the model. Particularly the development of aids for evaluating and determining problem complexity, and a means to determine the metaphorical distance between collaborators. These two key determinants drive the collaboration concepts for technology, people, policies, and processes / structures.

\section{Formulation}

In general, the speed, interconnectedness, and unpredictability of the business environment have resulted in a need for collaboration across industries and sectors. As such, alliances and cooperative strategies are increasingly common across most all industries; which has resulted in a blurring of traditional sector boundaries (i.e., Societal Sector Platform). Problems and opportunities previously siloed by sector are now meaningfully influenced by actions in adjacent sectors. Indeed, a blurring of sector boundaries is a likely outcome of the "interconnectedness" and unpredictability in the environment. As a result, previous conceptualizations framed from a dichotomy of "cross-sector" or "public private partnerships" and focusing on the exchange of resource (i.e. Resource Dependence Platform) or social issue (Social Issue Platform) may provide less utility as sector boundaries continue to blur.

During the formulation stage, organizations assess their motivation to collaborate. In doing so they must define the problem at hand, the purpose of collaboration. Through our interviews, we identified that organizations differ on this motivation - namely in terms of if they perceive incentives from the collaboration (i.e., evidence a promotion-focus) or seek to minimize risks (i.e., seek security and risk minimization). These differences often resulted in significant frictions between collaborating parties and ultimately destabilized and/or prematurely ended the collaborative activity. Thus, understanding that public/government organizations and private/non-government organizations often differ on these motivations in general; asking a private organization to engage in a minimal or 0-return on investment collaboration is likely going to require an understanding of what would motivate it to collaborate. Thus, this first stage in formulation - that of determining the rationale and motivation to collaborate- and it is important to the partnership model. This is particularly evident in a voluntary-based partnership environment, where organizations do not have to collaborate.
After assessing the rationale for the collaboration, the partnership formulation stage is determined by (1) the complexity of the problem and (2) the conceptual "collaborative distance" between the two organizations. Following this, certain structures and safeguards will be required.

\subsection{Problem Complexity}

Importantly, the attributes of the problem represent a central and often overlooked determinant in the structure and evolution of collaboration. By unpacking the specific characteristics of the problem, valuable insights are gained. Problems demonstrate varying degrees of complexity and definition $[4,14]$. Though there are several conceptualizations of problem complexity, we follow the majority and suggest the degree of problem complexity can be determined by the (1) number and (2) interaction of resources that are needed to successfully solve the problem. Resources refer to both tangible (e.g., plant, equipment, technology) and intangible (e.g., knowledge, expertise, insight) inputs. As such, solutions to less complex problems require either fewer resources or resources that can be applied separately with little integration (i.e., decomposability - the problem can be divided with relative ease into smaller sub-problems). Complex problems, in contrast, often necessitate the deployment of numerous resources involving a high level of integration.

Building on insights from transaction cost economics, which involves the study of a firm's decision to 'make' or 'buy' resources, Nickerson \& Zenger [10] posit as problem complexity increases, more hierarchical governance structures are needed. Less complex, decomposable problems that can be solved with few resources or limited integration are most effectively addressed with policies, interface documentation, and operational plans. However, complex, non-decomposable problems warrant hierarchical governance (e.g., joint teams, organizational integration). The appropriate alignment between problem complexity and collaborative structure enhances the effectiveness of the collaboration by eliminating potential hazards and facilitating the creation and transfer of resources.

Problem complexity plays a central role in determining the structure and technology requirements of the collaboration. An additional attribute determining the choice of governance is the degree to which the problem is clearly defined. Clearly defined, wellstructured problems are more readily identified and are often convergent in nature. According to Cropley [5], 
the goal of the convergent collaboration is to come to a correct answer to expected questions that does not require significant creativity. Convergent problem solving focuses on coming up with the single, wellestablished answer to a problem [5]. The process is oriented toward deriving the single best, or most often correct answer to a problem set. Convergent thinking emphasizes speed, accuracy, and logic and focuses on recognizing the familiar, reapplying techniques, and accumulating stored information. It is most effective in situations where an answer readily exists and simply needs to be either recalled or worked out through decision making strategies. Convergent processes dictate specific types of collaboration structures, technologies, and policies. The processes focus mainly on case matching and recognition of similarly- or identically-structured problems. Members engage in comparative analysis of expected and past cases and elicit potential responses to the situation based on isomorphic events where established solutions exist. Decisions are generally confined to selecting from established solutions and options. While these solutions may include an action, suitable solutions may also include no response or dissemination of information. The technology aiding this process should focus on matching appropriate cases and the outflow of information to the appropriate channels.

On the other hand, poorly-defined, ill-structured problems are difficult to identify and are divergent. Mitroff \& Emshoff [9] highlights three salient features of ill-defined problems: (1) no consensus by those who are assigned to address the problem as to an appropriate solution or strategy, (2) disagreement on how to proceed, and (3) no clear formulation of the problem itself. The generation of alternative options is based on prior mental models, conceptual combination of existing solutions, and problem definition. Similar to problem complexity, ill-defined problems are most effectively solved when paired with hierarchical governance structures that facilitate resource sharing and integration. In sum, our model suggests that problem complexity thus drives the structure of the collaboration.

\subsection{Collaborative Distance}

Collaborative distance captures the degree of similarity between the cooperating organizations across four separate levels of analysis: sector, organization, functional, and individual. Previous research investigating cross-sector alliances has largely adopted discrete conceptualizations of sectors, suggesting similarities between collaborating sectors are either present or absent. We propose that discrete conceptualizations of sectors are unnecessarily coarse (given the interconnectedness and complexity of the problems facing organizations) and that additional insights can be gained by conceptualizing the distance (i.e., degree of similarity) as a continuous measure. The codebook that details the four levels of collaborative distance and their measurement are available upon request.

Distance is captured in international research in terms of the similarity of institutions between the home and target country. Here, we borrow from this methodology and apply this conceptualization of distance to better capture the space between two organizations that are set to collaborate. Essentially, collaborative distance describes the notion that organizations, both public and private, have differences that dictate how similar or different they are prior to collaborating. For example, differences exist between domains of responsibility (e.g., regional, national). In addition, collaboration occurs laterally (e.g., national to national) as well as vertically (e.g., regional to national). During our interviews and focus groups, we found that there are a number of factors that arise as individuals assess the viability of a collaboration, such as the sector's regulatory environment as well as the organization's familiarity with collaboration; how the organization's leader viewed the importance of collaboration; as well as how well those individuals actually transacting in the collaboration interact. We categorized and extended these discussions to develop a measure that assists in capturing the differences between two organizations. How each organization is assessed in terms of these differences-and the objective differences between them on characteristics important for collaboration-comprises the construct we have labeled “Collaborative Distance.” Organizations that are very similar to each other are said to have "low collaborative distance" and organizations that differ on important characteristics are said to have "high collaborative distance." In other words, assessing the space or distance that organizations must traverse to jointly solve a problem is much more complex than simply assessing if they are public or private.

2.2.1. Sector. Every sector has distinct features that may impact a firm's willingness or ability to enter collaborative arrangements. For example, many organizations operating in the finance/banking sector are likely engaged in any number of cooperative alliances; whereas organizations operating in the Dams sector do not frequently engage in collaborative activities within or outside of its sector. Each sector differs in size, competitiveness, as well as in regulatory oversight. While organizations can and do encounter 
some of these sector-wide norms, sector-level influences are one dimension that may impact the collaborative distance between two organizations. If the organizations are from the same sector, this difference is nil; whereas organizations from distinct sectors may have additional barriers to overcome in determining appropriate safeguards.

2.2.2. Organization. A core assumption in strategy research is that an organization's resources and capabilities are heterogeneous, they differ from organization-to-organization, and that these resources and capabilities tend to be quite sticky, not easily transferred from one organization to another. As such, every organization has not only its own set of resources and capabilities, but also its own set of goals, expectations, motivations, and heuristics. And this bundle of attributes differs between organizationssometimes substantially (high collaborative distance), and other times very little (low collaborative distance). The magnitude of these differences will impact the type of safeguards organizations put in place to manage the collaboration. For instance, organizations with high distance will likely include a higher degree of formal controls (see discussion on safeguards below) than firms with lower distance. Again, organizations that have collaborated or had previous exchanges will bring a shared history that might lower distance. However, depending on the success of that collaboration the type of safeguards utilized will likely vary - with less successful prior exchanges dictating the need for more formal mechanisms and more successful exchanges utilizing more informal mechanisms since there is more likely to be a higher degree of trust between partners. Therefore, at the organizational-level, as Table 1 notes, there are a number of determinants organizations can evaluate to help capture how much distance exists between two organizations.

Table 1. Organizational Distance

\begin{tabular}{|l|l|}
\hline VARIABLES & TYPE \\
\hline Size & Secondary \\
\hline Age & Secondary \\
\hline Organizational structure & Mix \\
\hline Leadership & Mix \\
\hline \multicolumn{2}{|c|}{} \\
\hline $\begin{array}{l}\text { Degree of codification: publishing of } \\
\text { policies and procedures }\end{array}$ & Primary \\
\hline Strength of Regulations: Sanctioning & Primary \\
\hline \multicolumn{2}{|c|}{ Informal Institutions } \\
\hline Frequency of Collaboration & Mix \\
\hline \% of R\&D: Norm of collaboration & Mix \\
\hline $\begin{array}{l}\text { Number \& Participation in Industry } \\
\text { Associations }\end{array}$ & Primary \\
\hline Leadership & Primary \\
\hline
\end{tabular}

2.2.3. Functional. We identified that the characteristics of the people associated with the collaboration are also important to assess. There exists functional-level coordination in collaboration activities. Here the focus is on how disparate the job functions of the groups/individuals involved in the collaboration. For example, if a technical person is involved for organization A, and a policy person for organization B, the level of information sharing may be limited due to a lack of common language. This in turn creates a higher distance between the two organizations. A resolution would be to perhaps include additional personnel in other functional roles that could help with the translation, essentially lowering the distance. Table 2 underscores two separate job classification systems that help frame how persons in different occupational roles differ. Depending on the distance between those functions that will be involved in the collaboration, more or less formal safeguards will be specified.

Table 2. Functional Distance

\begin{tabular}{|l|l|}
\hline VARIABLES & TYPE \\
\hline Job Title & Secondary \\
\hline Thinking Creatively & Secondary \\
\hline Technicality & Secondary \\
\hline People Skills & Secondary \\
\hline Decision-Making Authority & Mix \\
\hline
\end{tabular}

2.2.4. Individual. Though the focus here is on organizational collaboration, individuals play a critical role in the actual success of the collaboration. Similar to the functional-level variables, here it is important to identify the distance between critical personnel. In other words, managers responsible for the collaboration should be assessed based on their personality and background. For instance, if the two persons in charge of the day-to-day management have a shared history (e.g., belong to the same country club or fraternity), the distance between the two organizations will be lowered as a result, despite perhaps great distance at the organizational level. Alternatively, if the two individuals have strong personalities and are not high on agreeableness, even though the organizational distance might be lower, the differences at the individual level may increase this distance. Therefore, the individual level distance not only impacts the specification of the safeguards, but also interacts with the other levels of distance. 


\section{Notional Collaborative Distance Calculations}

To provide some initial data about the viability of Collaborative Distance, we assessed a notional partnership: San Diego Water Authority and Poseidon Resources. This case was selected due to heightened awareness and concern regarding water shortages across the nation, particularly in California. Poseidon Resources Corporation develops and finances seawater desalination and water infrastructure projects, one of their current projects is a 50-million-gallon a day desalination plant in Carlsbad, California. We selected this particular partnership because they represent organizations collaborating to solve important challenges. Until the first half of the $20^{\text {th }}$ century, water supply (and sanitation) was a local government responsibility. Changes brought about with Federal Water Pollution Control Act of 1948; the Clean Water Act of 1972 and the 1987 Water Quality Act as well as the formation of the Environmental Protection Agency changed the scope of the partnerships and how Americans receive their water. Over 73 million Americans receive water service from a privately owned water utility or a municipal utility operating under a public-private partnership. Private water companies own about $16 \%$ of the nation's community water systems. Utilizing the codebooks, we analyzed each partner in the collaboration and used the Euclidian distance algorithm to calculate Collaborative Distance based on n-tuple vectors, as denoted in Figure 2. When we used secondary sources to assess Euclidian Distance across Sector, Organization, Functional, and Personal characteristics, we found that the total "Collaborative Distance” was relatively low between San Diego Water Authority and Poseidon Resources. Figure 2 illustrates the Collaborative Distance.

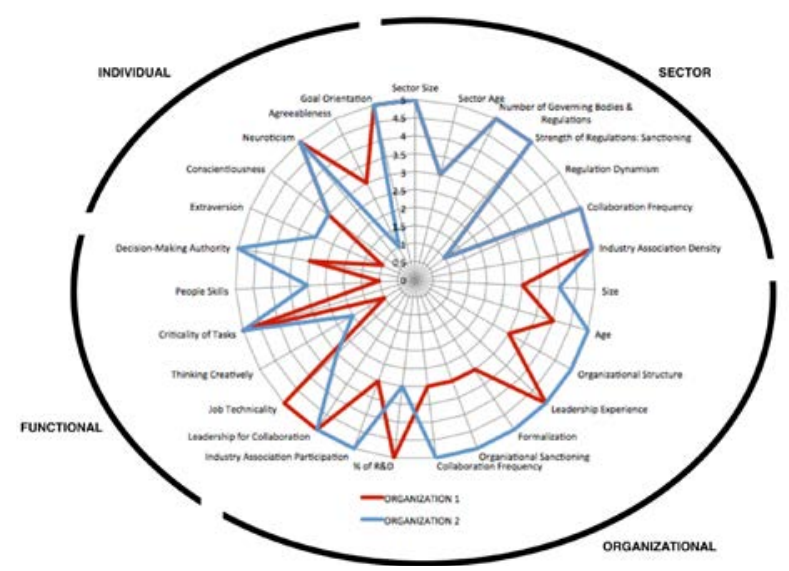

Figure 2. Collaborative Distance
The Total Collaborative Distance $\left(\mathrm{CD}_{\mathrm{T}}\right)$ between these two organizations is relatively low $\left(\mathrm{CD}_{\mathrm{T}}=6.86\right)$, indicating that these organizations have similarities across sector, organizational, functional, and personal levels. First, because these organizations both operate in the water and waste management sector, they have 0 differences on measures of sector differences (e.g., they operate under the same legal authorities; have same industry standards and norms, etc.). However, as one of them is a private company (Poseidon), we do see some differences in Organizational Collaborative Distance $\left(C D_{0}\right)$. For example, American Water is the largest, investor-owned water and wastewater utility in the U.S. and it has been around for a century. It 'grew-up' with public utilities and we see much similarity between this organization and a public utility. As new private utilities come online - organizational distance between these organizations and public firms will likely be greater due to new norms and less overlap between organization functions. One example is Poseidon Water, which is developing the largest desalination plant in the Western Hemisphere. As Poseidon invests heavily in R\&D and hires new engineers with limited water background, we would expect the $\mathrm{CD}_{\mathrm{O}}$ to increase. Thus, it is important that the San Diego Water Authority (and other public water utilities partnering with Poseidon) engaged in information sharing early and build trust as to lessen impact on $\mathrm{CD}_{\mathrm{O}}$ as the organizations change. We see that this is occurring right now as San Diego Water Authority has agreed to purchase a set amount of water - at a specified amount (\$2,000 per acre-foot) - from Poseidon Water, which is not yet finished with construction. The Water Authority has worked with Poseidon throughout its proposed inception in CA.

Where we see other differences lies in the Functional Collaborative Distance $\left(\mathrm{CD}_{\mathrm{F}}\right)$ and the Personal Collaborative Distance $\left(\mathrm{CD}_{\mathrm{P}}\right)$. This is likely due to the nature of the people and roles that are tasked with managing the partnership. These two organizations have different pay scales, job roles, and attract different types of personalities. As Poseidon is heavy in R\&D, it has attracted younger, more innovative employees who are highly technical. This can lead to some levels of distance. One intervention might then be to examine who is selected to manage the partnership to minimize differences, while another intervention may be to create teambuilding exercises early to create shared experiences and foster more collaboration among these two people from different backgrounds and organizations. 


\section{Structures and Safeguards}

Given that the nature of the problem this partnership faces is highly complex and the collaborative distance is relatively low, we can begin to make some recommendations about the type of safeguards/control mechanisms needed and the type of collaboration structure needed for this partnership to be successful. Figure 3 depicts the relationship between Collaborative Distance, Problem Complexity, Safeguards, and Collaboration Structures.

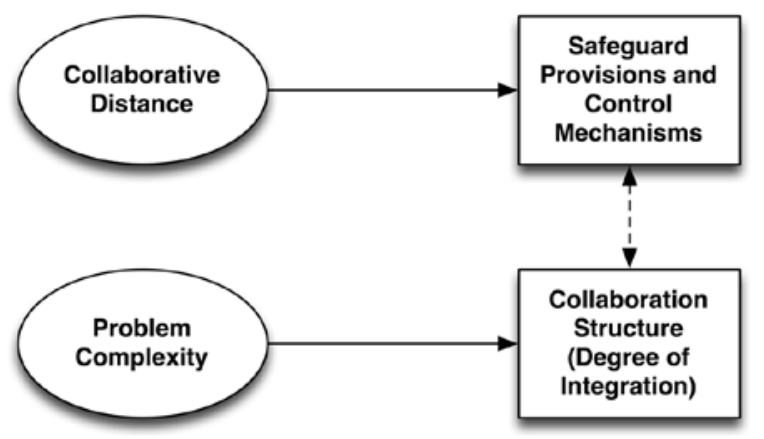

Figure 3. Relationship between Collaborative Distance/Complexity and Structures/Control Mechanisms

Asymmetry exists in an organization's abilities to exert power and control over another organization and its resources [11]. As such, effective cooperation requires mutual recognition of these differences. The structure and safeguards defined for a given collaboration help address these asymmetries.

\subsection{Structures}

Structure references the specific governance mechanisms in the cooperative exchange or alliance. The formal development of governance structures and their respective strengths and weaknesses can be readily traced to Oliver Williamson's work in transaction cost economics $[16,17,18]$. While a comprehensive review of transaction cost economics is beyond the scope of the current report a brief introduction with examples is helpful in illustrating the proposed relationships between problem complexity, collaborative distance, and alliance structure. Williamson [16] distinguishes between three types of governance structures: market, hybrid and hierarchy.

Market governance is characterized by high-powered incentives and adaptability (i.e. flexibility). An example of an alliance structured with a market governance mechanism is a legal agreement between two organizations to distribute, license or export a particular product - the rules governing the exchange are dictated by contract law, each party is highly incentivized to act in their best interest and the nature of the relationship is adaptable, suggesting the terms of the contract can be changed or renegotiated at minimal costs.

Hierarchical governance, in contrast, is characterized by low powered incentives and adaptability. An example of an alliance structured with hierarchical governance is a joint venture - two organizations collaborate by forming a new legally independent organization. The rules governing the exchange within the joint venture are developed and administered internally within the governing body of the organization. While hierarchical governance structures are less adaptable, they can effectively reduce the threat of opportunistic behavior [16] and facilitate knowledge sharing and integration, critical processes for addressing complex and ill-defined problems [10]. In summary, governance structures can be meaningfully arranged on a spectrum from market to hierarchy with market structures providing more adaptability and efficiency when coupled with less complex and clearly defined problems and hierarchical structures providing more efficiency when paired with complex and ill-defined problems requiring knowledge sharing and integration.

\subsection{Safeguards}

Safeguards reference the formal and informal mechanisms in an alliance that further stabilize the collaboration. Safeguards operate within the chosen governance structure allowing the collaborating parties to "fine tune" the nature of the exchange. Examples of formal safeguards include: contract clauses specifying information sharing procedures and routines, development of joint teams, monitoring of the alliance partners, and credible commitments of time and capital. Greater specification typically increases the complexity of the contract, which is costly $[7,13]$.

Informal safeguards are often not specified in the agreement and are less tangible. Examples of informal safeguards include: the level of trust between collaborating parties, the reputation of an organization, as well as shared values and beliefs. Safeguards play a central role in stabilizing alliance performance as cooperative distance increases. Such relational arrangements are argued to help prevent against opportunistic hazards [13]. Organizations in alliances with a high cooperative distance are inherently less similar suggesting additional safeguards are needed to ensure effective collaboration. 


\section{Cross-Sector Integrative Framework}

Problem attributes and collaborative distance combine to determine both the structure and safeguards needed to enhance alliance performance. Problem complexity and definition inform the choice of governance while collaborative distance determines the relevance of safeguards (as shown in figure 4).

- Less complex, well-defined problems with low collaborative distance between collaborating partners (i.e., similar firms) result in market governance structures and few safeguards.

- Less complex, well-defined problems with high collaborative distance result in market governance structures and many safeguards.

- Complex, ill-defined problems with low collaborative distance (i.e., similar firms) result in hierarchical (i.e. integrated) governance structures and few safeguards.

- Complex, ill-defined problems with high collaborative distance result in hierarchical (i.e. integrated) governance structures and many safeguards.

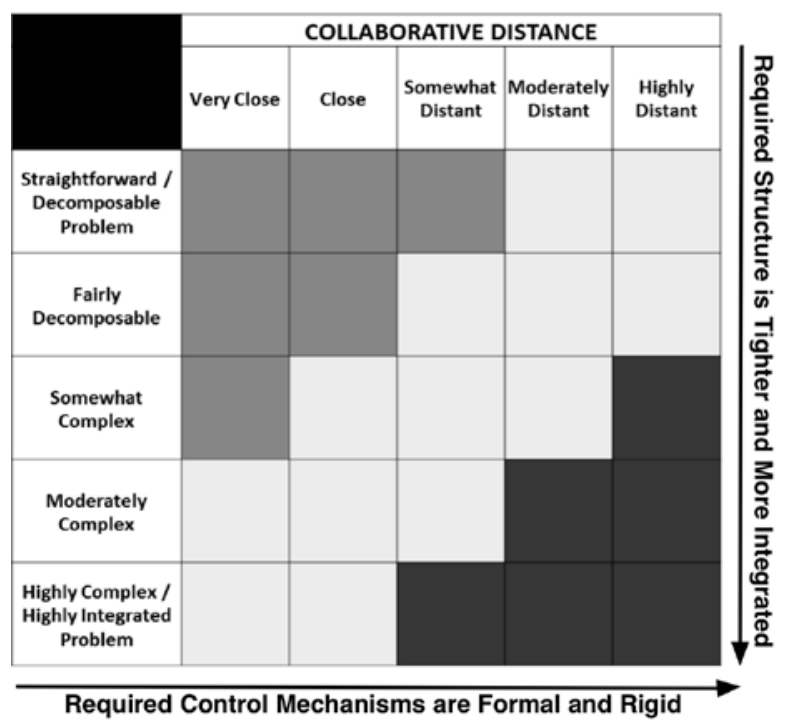

Figure 4. Recommendations for Control Mechanisms and Structure

One way to classify problem complexity and level of integration required is to examine the sector critical infrastructure identified research and development needs. Synthesizing the framework, Figure 5 depicts sample control mechanisms based on Collaborative Distance and Problem Complexity.

\begin{tabular}{|c|c|c|c|}
\hline & \multicolumn{2}{|c|}{ COLLABORATIVE DISTANCE } \\
\hline & & Low & High \\
\hline \multirow{2}{*}{ 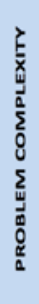 } & Low & $\begin{array}{l}\text { - Trust } \\
\text { - Reputation } \\
\text { - Shared beliefts and values } \\
\text { - Indudes all relational components }\end{array}$ & $\begin{array}{l}\text { - Formal contractual commitments of time and capital } \\
\text { - Explicit and binding specification of promises, } \\
\text { obligations, and processes for dispute resolution } \\
\text { - Formal monitoring }\end{array}$ \\
\hline & High & $\begin{array}{l}\text { - Informal agreements } \\
\text { - Memorandums of understanding } \\
\text { - Joint teams with loose monitoring }\end{array}$ & $\begin{array}{l}\text { - Resource sharing protocols and routines } \\
\text { - Joint teams } \\
\text { - Specification of promises, obligations, and processes for } \\
\text { dispute resolution } \\
\text { - Formal monitoring }\end{array}$ \\
\hline
\end{tabular}

Figure 5. Sample Control Mechanisms Based on Collaborative Distance and Problem Complexity

\section{Implementation}

Following the formulation process, the next stage is the actual collaboration activities. These activities will have been specified during the formulation stage and should now be actively managed during the Implementation Stage. It is during the implementation stage that the structure and safeguards that were specified during formulation can be evaluated.

\subsection{Joint Action}

In a well-structured collaboration, an implementation plan is developed during the formulation stage so that the organizations can hit the ground running. The implementation plan includes specific action plans, with specified resources. Those individuals that are integral to the day-to-day operations will also have been involved in the process. Another part of the implementation plan includes processes outlined for conflict-management. Because lack of strategic alignment is a key cause of failure, it is important for firms to periodically check to ensure alignment and that both organizations have the same vision and interest in the collaboration. Both formal and informal safeguards are mechanisms through which organizations will execute and evaluate this stage. Organizations will monitor, share information, and participate in ongoing evaluation of the collaboration.

\subsection{Resources}

Our interviews with SMEs indicated that organizations should invest in resources to support PPPs. Some ideas put forth from the SMEs were to have dedicated working groups across organizations, delineated authority and responsibility, and shared space to collaborate. 


\section{Outcomes and Evaluation}

Measuring the results of collaboration is critical, and evaluation of whether the collaboration is achieving its objectives should be done periodically throughout the life of the collaboration. Both quantitative and qualitative metrics should be considered, yet the qualitative criteria (i.e., level of trust) can be quite difficult to measure. In the strategic alliance literature, typically performance is considered from one of three perspectives, (1) financial, (2) operational, or (3) organizational effectiveness [2]. It is understood that financial performance is not always relevant to strategic alliances [1], rather operational and organizational success factors are often the focal points of the collaboration, and organizational effectiveness is noted to encompass operational performance. When trying to measure organizational effectiveness in terms of collaboration performance, however, a multipleconstituencies approach is needed because there are at least two parties to any collaboration, which is where challenges may arise. However, while we note these challenges, we have also identified analytical criteria to assess the effectiveness of inter-organizational collaboration. Some of these include process and outcome satisfaction from individuals in the collaborating organizations (e.g., willingness to continue the partnership, perceived progress toward jointly defined goals), and some are related to organizational resiliency (i.e., situation awareness of roles and responsibilities, recovery priorities, understanding and analysis of hazards, connectivity awareness, exercise participation, governance structures [8].

\subsection{Challenges}

Assessing performance outcomes of collaboration between organizations can be difficult. For example, in evaluating the performance outcomes of alliances we face challenges in obtaining data on returns (especially when organizations are not public entities) as well as in the ability to tie returns to specific deals and transactions. Even when we specify the type of collaboration, such as technology development, it can be difficult to determine a viable cut-off period in which to evaluate performance that is meaningful across organizations, especially considering that the nature of the collaboration agreement varies across deals (i.e., contract terms, safeguards, etc.). Therefore, the challenge in determining collaboration performance stems from the fact that each collaboration is unique and two separate parties are evaluating the collaboration, often using differing criteria. Despite this, we have identified a way to address some of these challenges through the development of an iterative, recursive process.

\subsection{Measures}

Organizational effectiveness measures assess the degree of fulfilment of several goals from the perspective of one collaborator. One of the most frequently used measures is a partner's satisfaction with the overall performance $[3,6,12]$. Similarly, a measure of the degree of fulfilment of strategic goals and the net spillover effects on other activities are also assessed. These three measures often impact the longevity of the collaboration, whether contractual changes will arise, as well as its overall survival [2].

\subsection{Feedback}

The most important component of our model was the recursive nature of collaboration. Partnerships are not static; changes in collaborative distance should arise as time and experience with each other occurs through problem solving and time. Thus, it is important to note that there is a feedback loop that can change the motivation to collaborate and future safeguards and structures needed. This was evident in our case study of the water and wastewater management sector in California; because private companies have partnered with public utilities for such a long time, there is much less collaborative distance at the organization level.

\section{Conclusion}

The framework makes the following recommendations for establishing collaborations:

1. Define Problem to Be Solved. Is the problem welldefined and technically known? Or is the problem ill-defined and complex? Does the problem address issues identified as high priority, critical needs for NCI sectors?

2. Match Structure to Problem. High complexity, illdefined problems require structures that allow for tight integration among partners, often including shared workspace, incentives for joint problem solving, and interdependent tasks. These problems will need the most planning for joint control mechanisms, while more straightforward problems require information sharing mechanisms only.

3. Understand Collaborative Distance. Are the partners in the same sector? What differences in 
organizational characteristics might drive behavior (e.g., security focus or promotion focus?)? What partnership experiences do the individuals participating in the collaboration have? Is the person tasked with the partnership more technical or policy-focused? What personality characteristics among the individuals partnering may impact collaboration? Do you have the right people at the table making decisions about the partnership outcomes?

4. Set up Safeguards to Foster Trust. When high collaborative distance exists based on above questions, set up safeguards to increase trust among partnering organizations. Spend more time upfront on contractual mechanisms and safeguards.

5. Determine Evaluation Metrics. Determine up front the outcomes you would like to see from the partnership. Don't form partnerships just to partner, collaborate to solve problems.

\section{References}

[1] Anderson, E. Two Firms, One Frontier: On Assessing Joint Venture Performance. MIT Sloan Management Review 31, 2 (1990), 19.

[2] Ariño, A. Measures of Strategic Alliance Performance: An Analysis of Construct Validity. Journal of International Business Studies 34, 1 (2003), 66-79.

[3] Beamish, P. Multinational Joint Ventures in Developing Countries. Routledge, 2013.

[4] Camillus, J.C. Strategy as a Wicked Problem. Harvard Business Review 86, 5 (2008), 98-106.

[5] Cropley, A. In Praise of Convergent Thinking. Creativity Research Journal 18, 3 (2006), 391-404.

[6] Lin, X. and Germain, R. Sustaining Satisfactory Joint Venture Relationships: The Role of Conflict Resolution Strategy. Journal of International Business Studies 29, 1 (1998), 179-196.

[7] Mayer, K.J. and Argyres, N.S. Learning to contract: Evidence from the Personal Computer Industry. Organization Science 15, 4 (2004), 394-410.

[8] McManus, D.J. A Model of Organizational Innovation: Build Versus Buy in the Decision Stage. The International Journal of Applied Management and Technology 1, 1 (2003), 29-44.

[9] Mitroff, I.I. and Emshoff, J.R. On Strategic Assumptionmaking: A Dialectical Approach to Policy and Planning.
Academy of Management Review 4, 1 (1979), 1-12.

[10] Nickerson, J.A. and Zenger, T.R. A Knowledge-based Theory of the Firm-The Problem-solving Perspective. Organization Science 15, 6 (2004), 617-632.

[11] Oliver, C. Determinants of Interorganizational Relationships: Integration and Future Directions. Academy of management review 15, 2 (1990), 241-265.

[12] Parkhe, A. Strategic Alliance Structuring: A Game Theoretic and Transaction Cost Examination of Interfirm Cooperation. Academy of Management Journal 36, 4 (1993), 794-829.

[13] Poppo, L. and Zenger, T. Do Formal Contracts and Relational Governance Function as Substitutes or Complements? Strategic management journal 23, 8 (2002), 707-725.

[14] Simon, H.A. Theories of Bounded Rationality. In Decision and Organization. Elsevier, Amsterdam, 1972, 161175.

[15] Trafford, S. and Proctor, T. Successful Joint Venture Partnerships: Public口Private Partnerships. International Journal of Public Sector Management 19, 2 (2006), 117-129.

[16] Williamson, O.E. Markets and Hierarchies. New York, (1975), 26-30.

[17] Williamson, O.E. The Economics of Organization: The Transaction Cost Approach. American Journal of Sociology, (1981), 548-577.

[18] Williamson, O.E. Transaction Cost Economics: The Comparative Contracting Perspective. Journal of Economic Behavior \& Organization 8, 4 (1987), 617-625. 